\title{
Anotações do enfermeiro no acompanhamento do crescimento e desenvolvimento infantil*
}

\author{
Nurses' notes on child growth and development \\ Anotaciones del enfermero en el acompañamiento del crecimiento y desarrollo infantil
}

Valéria Conceição de Oliveira ${ }^{1}$, Matilde Meire Miranda Cadette ${ }^{2}$

\begin{abstract}
RESUMO
Objetivo: Compreender o significado que o enfermeiro atribui às anotações de enfermagem, na realização do acompanhamento do crescimento e desenvolvimento de crianças de zero a cinco anos em unidades básicas de saúde na cidade de Divinópolis - Minas Gerais. Métodos: A abordagem fenomenológica foi a trajetória que sustentou esta pesquisa e a coleta de dados foi feita através de entrevista aberta com nove enfermeiras. Resultados: Da análise compreensiva dos discursos emergiu a categoria de análise relacionada às finalidades dos registros/ anotações de enfermagem. As entrevistadas descreveram o registro de enfermagem como documento legal, como instrumento para acompanhar o estado de saúde da criança, como substrato para a equipe multiprofissional e como um norteador para a construção do diagnóstico de saúde da comunidade. Conclusão: Os resultados mostraram que, apesar de as enfermeiras conhecerem e relatarem sobre a importância das suas anotações para a continuidade do cuidado à criança, delas se constituírem em documento legal, de subsidiarem o trabalho de outros profissionais, elas continuam produzindo registros incompletos e vazios de significado.

Descritores: Registros de enfermagem; Cuidado da criança; Saúde da criança; Enfermagem pediátrica; Desenvolvimento infantil
\end{abstract}

\begin{abstract}
Objective: The objective of this study was to understand the relevance of nurses' notes on the growth and development of children aged 0 to 5 years attending a primary healthcare unit in Divinópolis, Minas Gerais. Methods: A phenomenological approach was used to conduct the study. Data were collected through unstructured interviews with 9 registered nurses. Results: Nurses' notes were the main category emerging from the data. Nurses' notes were described as legal documentation, as a fundamental instrument to facilitate the follow-up of child's health by a multidisciplinary healthcare team, and as an essential element to assess the health of the community. Conclusion: Despite nurses valuing nurses' notes as a legal documentation and relevant for child's care, some of the nurses' notes continue to be incomplete and meaningless records.
\end{abstract}

Keywords: Nursing records; Child care; Child health; Pediatric nursing; Child development

\section{RESUMEN}

Objetivo: Comprender el significado que el enfermero atribuye a las anotaciones de enfermería, en la realización del acompañamiento del crecimiento y desarrollo de niños de cero a cinco años en unidades básicas de salud en la ciudad de Divinópolis - Minas Gerais. Métodos: El abordaje fenomenológico fue la trayectoria que sustentó esta investigación y la recolección de datos se llevó a cabo a través de una entrevista abierta a nueve enfermeras. Resultados: Del análisis comprensivo de los discursos emergió la categoría de análisis relacionada a las finalidades de los registros/anotaciones de enfermería. Las entrevistadas describieron el registro de enfermería como documento legal, como instrumento para acompañar el estado de salud del niño, como sustrato para el equipo multiprofesional y como norteador para la construcción del diagnóstico de salud de la comunidad. Conclusión: Los resultados mostraron que, a pesar de que las enfermeras conozcan y relaten respecto a la importancia de sus anotaciones para la continuidad del cuidado al niño, de que éstas se constituyan en un documento legal, de que subsidien el trabajo de otros profesionales, ellas continúan produciendo registros incompletos y carentes de significado.

Descriptores: Registro de la enfermería; Cuidado del nino; Salud del niño; Enfermería pediátrica; Desarrollo infantil

\footnotetext{
* Trabalho extraído da Dissertação de Mestrado "Anotações do enfermeiro no acompanbamento do crescimento e desenvolvimento infantil: um estudo compreensivo" apresentada à Universidade Federal de Minas Gerais - UFMG - Belo Horizonte (MG), Brasil.

${ }^{1}$ Mestre em Enfermagem, Professora do Curso Enfermagem e Medicina da Universidade Federal de São João del Rei - UFSJ - Campus Centro Oeste Dona Lindu - Divinópolis (MG), Brasil.

${ }^{2}$ Doutora em Enfermagem, Professora da Escola de Enfermagem da Universidade Federal de Minas Gerais - UFMG - Belo Horizonte (MG), Brasil.
} 


\section{INTRODUÇÃO}

A anotação de enfermagem é um dos mais importantes instrumentos de comunicação. A comunicação, quer seja através da linguagem oral ou escrita, é imprescindível para a prática da enfermagem ${ }^{(1)}$. Entende-se que os registros são elementos imprescindíveis no processo do cuidar humano e, quando redigidos de maneira que retratam a realidade a ser documentada, possibilitam a comunicação permanente, podendo destinar-se a diversos fins como ensino, pesquisas, auditorias, processos jurídicos, planejamento e outros ${ }^{(2)}$.

É indiscutível a necessidade de registros adequados e freqüentes no prontuário do cliente. As anotações registradas pela equipe de enfermagem consistem no mais importante instrumento de avaliação da qualidade de atuação da enfermagem, e representam 50\% das informações inerentes ao cuidado do cliente registradas no prontuário ${ }^{(3)}$.

Cabe mencionar, entretanto, que apesar de todos os dados existentes explicitarem sobre a importância dos registros de enfermagem, quer seja para avaliação clínica do ser humano, quer seja para questões administrativas ou éticas legais, carecem de conteúdo científico, de consistência e, muitas vezes, de significado, pois, às vezes, observa-se desvalorização das anotações.

Nesta mesma direção, muitos autores têm discutido que os profissionais de enfermagem não dão a importância devida aos registros como fonte de comunicação, como meio para avaliação da assistência prestada ao cliente e como um documento que serve de elemento comprobatório da aplicação das teorias de enfermagem à prática ${ }^{(1,3-7)}$.

A minha preocupação com os registros de enfermagem no acompanhamento do crescimento e desenvolvimento infantil nas unidades básicas de saúde do município de Divinópolis - Minas Gerais, surgiu ao exercer a prática profissional como docente, quando começaram vários questionamentos dos alunos que iniciavam o estágio ensino clínico referentes a "pobreza dos dados" registrados no prontuário, tanto quantitativa como qualitativamente.

Diante disto, percebi que as anotações das enfermeiras eram deficientes, desprovidas de linguagem científica, com omissão de dados importantes da evolução da criança, não permitindo, por conseguinte, fazer uma avaliação do crescimento e desenvolvimento (CD) nas consultas subseqüentes, comprometendo, dessa forma, a qualidade da assistência e os objetivos dessa ação básica de saúde. Algumas anotações referentes às condições clínicas da criança eram registradas de forma monossilábica, como: "exame físico Ok", "NDN" (nada digno de nota), "sem anormalidades". Estas características do registro deixam dúvidas quanto a realização da avaliação das condições da criança para se chegar a estas afirmações.
A consulta de enfermagem para o acompanhamento do CD infantil é uma atividade incorporada às ações de atenção primária à saúde, haja vista que constitui um modelo assistencial adequado às necessidades de saúde da população. Deve ser realizada sistematicamente, acompanhando as etapas do processo de enfermagem ${ }^{(8)}$.

Dessa forma, compreende a entrevista para a coleta dos dados, o exame físico cefalalocaudal, devendo abranger as etapas correspondentes à inspeção, palpação, percussão e ausculta, conforme a necessidade do órgão ou sistema a ser avaliado, o estabelecimento dos diagnósticos de enfermagem, a prescrição, a implementação dos cuidados e a orientação das ações relativas aos problemas detectados ${ }^{(8)}$.

O acompanhamento da criança prevê várias consultas durante os primeiros anos de vida. Caso os dados obtidos não sejam registrados, a finalidade desse acompanhamento perderá a razão de ser, pois prescinde de significado. Em que parâmetros o enfermeiro poderá avaliar se a criança está crescendo e se desenvolvendo dentro dos padrões da normalidade ou se requer um encaminhamento, um retorno mais próximo ou um cuidar de diferentes profissionais da saúde?

Um acompanhamento do CD bem realizado não se baseia somente na anotação dos dados antropométricos, precisa estar alicerçado em todas as etapas da consulta de enfermagem. Nesse sentido, percebe-se a importância do enfermeiro compreender e apreender a forma como o processo de comunicação escrita ocorre, e os elementos que compõem este processo(6).

Reconhecemos que são várias as dificuldades apresentadas pela enfermeira na realização de um registro qualificado, científico e que visualize o cuidado individualizado, mas se a assistência não for registrada, fica no plano da oralidade, invisível ${ }^{(9)}$.

Isto posto, o objetivo deste estudo foi o de compreender o significado que a enfermeira atribui ao registro de suas ações, quando realiza o acompanhamento do crescimento e desenvolvimento de crianças de zero a cinco anos nas unidades básicas de saúde na cidade de Divinópolis - Minas Gerais.

\section{MÉTODOS}

O presente artigo foi elaborado a partir da dissertação de mestrado intitulada "Anotações do enfermeiro no acompanhamento do crescimento e desenvolvimento infantil: um estudo compreensivo", apresentada ao Curso de Mestrado em Enfermagem da Escola Enfermagem da Universidade Federal de Minas Gerais - Belo Horizonte, 2003.

A trajetória do estudo foi conduzida segundo o referencial fenomenológico que possibilita a compreensão do fenômeno estudado no contexto em que ele acontece, a partir dos sujeitos que o vivenciam, isenta de préconceitos.

A fenomenologia tem, como objeto de investigação, 
o fenômeno, isto é, aquilo que se mostra para o sujeito que o interroga, não em um primeiro olhar, mas através da busca incessante, rigorosa e atenta deste sujeito, na procura da "essência", ou seja, o que é característico, básico do fenômeno ${ }^{(10)}$.

O referencial filosófico utilizado para fundamentar a reflexão foi o do pensador Martin Heidegger, focalizando o cuidado enquanto característica fundante e estruturante do ser humano.

A fenomenologia heidggeriana busca o significado do fenômeno na existência, na facticidade e a partir do "ser-aí". O ser humano relaciona-se tanto com as coisas, quanto com as pessoas. Esse relacionamento com outros seres humanos, numa maneira envolvente e significante, é chamado de solicitude ou cuidado, é o preocupar-se com os outros ${ }^{(11)}$.

Nesse sentido, o cuidado do acompanhamento ao crescimento e desenvolvimento da criança envolve as anotações do enfermeiro. Quando anoto, estou cuidando para que o outro possa dar continuidade a esse acompanhamento, estou prestando um cuidado de enfermagem individualizado e de qualidade.

A região de inquérito foi constituída pelas unidades básicas de saúde (UBS) da Prefeitura Municipal de Divinópolis, Minas Gerais, onde se encontram inseridos os enfermeiros que acompanham o crescimento e desenvolvimento infantil.

As enfermeiras sujeitos dessa pesquisa foram convidados a participar do estudo; assinaram o Termo de Consentimento Livre e Esclarecido para o registro de seus depoimentos o qual lhes garantia o anonimato, visando proteger a sua privacidade. O critério de inclusão dessas enfermeiras foi o de já ter realizado o acompanhamento do CD infantil por seis meses ou mais.

Os discursos foram colhidos por mim, após contatos prévios e agendamentos específicos com as enfermeiras que aceitaram participar do estudo, em local que garantia a sua privacidade e silêncio para captação do dizer de cada um. Algumas entrevistas foram realizadas nas UBS, local de trabalho dos sujeitos entrevistados. Outros optaram por serem entrevistados em suas residências.

$\mathrm{Na}$ pesquisa qualitativa não há um número predeterminado de sujeitos a serem entrevistados. No momento em que as descrições tendem a evocar significados equivalentes percebidos pelo pesquisador, o mesmo se dá por satisfeito, considerando que os conhecimentos obtidos permitiram que o fenômeno se mostrasse.

Foram obtidos nove discursos por meio da seguinte questão norteadora: "Descreva o que significa para você o registro da sua consulta no acompanhamento do crescimento e desenvolvimento infantil".

Os discursos, depois de coletados, foram transcritos e analisados, seguidos os passos preconizados: leitura global do depoimento, extração das unidades de significado, unidades de significado transformadas, convergência e divergência de sentido ${ }^{(12)}$. Foram identificadas cinco categorias de análises dentre as quais apenas, uma das categorias abertas é tema deste artigo.

Este estudo foi realizado com a observância da Resolução

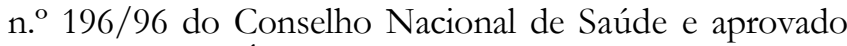
pelo Comitê de Ética em Pesquisa da Universidade Federal de Minas Gerais.

\section{RESULTADOS}

A categoria de análise apreendida, relacionada às finalidades dos registros de enfermagem, é um recorte dos resultados da Dissertação de Mestrado.

Os sujeitos entrevistados descreveram o registro de enfermagem como documento legal, como instrumento para acompanhar o estado de saúde da criança, como substrato para a equipe multiprofissional. Uma outra finalidade, evidenciada na fala de uma entrevistada, foi o registro de enfermagem como um norteador para a construção do diagnóstico de saúde da comunidade, o que permitiria a prestação de um cuidado de enfermagem dirigido às necessidades da população adstrita à área de abrangência da UBS.

\section{Registro de enfermagem: documento legal e auditoria}

Apreendo dos relatos das enfermeiras entrevistadas que os registros de enfermagem constituem documento legal da assistência prestada à criança.

Essas anotações têm que ser coerentes e bem concisas para se ter um trabalho sério [...] uma coisa que tenha valor legal (E7).

Um outro fato que merece ser destacado na fala das entrevistadas diz respeito ao registro como comprovação do trabalho realizado, como forma de se "resguardar" de problemas futuros.

Como já teve caso assim, de encaminhar uma criança para a estimulação, e a mãe não a levou. Se houver qualquer problema, você pelo menos fica resguardada, você tem tudo anotado no prontuário, com a data e assinatura (E4).

Porém, o que nos chama a atenção, e o que se tem verificado na prática, é que, às vezes, o profissional nem assina o que escreveu, prejudicando a preservação do documento e comprometendo a autonomia profissional. Uma entrevistada parece ter essa percepção quando nos fala:

[...] e muitas vezes nem assina. Assinar é o mais importante ainda. Se você escreveu, não assina, não coloca o seu registro, é uma falha. Já percebi isso muito (E4).

Outra faceta desvelada nos relatos refere-se aos 
registros de enfermagem como função avaliativa da qualidade da assistência prestada ao cliente, da identificação dos aspectos deficientes para melhoria dessa assistência e do fornecimento de dados para levantamentos estatísticos e pesquisa. Em síntese, poderíamos afirmar que a entrevistada está se referindo ao registro como instrumento de auditoria em enfermagem:

É importante para o serviço esse relatório que a gente faそ, essas anotaçôs, porque a partir dai desenvolve-se o trabalho nosso, melhorase as questões do atendimento, fazem-se alguns levantamentos, servem como fonte de pesquisa, trabalhos estatísticos, modificação no plano de trabalho (E9).

\section{Registro de enfermagem na Construção do diagnóstico comunitário de saúde}

O discurso a seguir salienta a necessidade dos registros de enfermagem no prontuário da criança, para construir o perfil de saúde/doença de sua população e organizar a assistência de enfermagem pautada nas necessidades da clientela.

Então eu preciso conhecer essa área de abrangência, a minha área de abrangência, o modo de vida dessas crianças para poder trabalhar com elas conforme a necessidade de cada uma. Então, sem o registro eu não tenho como fazer este tipo de trabalho, ajudando a comunidade e as crianças a terem um nivel de vida melhor, uma sobrevida boa. Através dos registros é que eu realmente posso trabalhar pensando no bem-estar dessa criança (E2).

A fala da enfermeira nos remete a uma importante finalidade dos registros de enfermagem, o de planejar a assistência de enfermagem baseada no perfil epidemiológico da população da área de abrangência da UBS.

\section{Registro de enfermagem: acompanhar o estado de saúde da criança}

Averiguou-se, ainda, nas falas a seguir, que os registros de enfermagem possibilitam o acompanhamento do estado de saúde da criança:

O registro, ele é importante para nós podermos observar e acompanhar o desenvolvimento da criança (E2).

Acho a maior validade porque eu tenho o acompanbamento da criança (E4).

Observamos que os entrevistados corroboraram a idéia de que acompanhar o estado de saúde da criança é "cuidar" para que ela atinja o crescimento pessoal e social e, para isso, é necessário que a enfermeira conheça e tenha domínio dos procedimentos que integram a consulta de enfermagem, a fim de desempenhar um cuidar sistematizado, ordenado, autêntico e solícito.

A finalidade do acompanhamento do CD infantil é o de vigilância à saúde da criança. Assim emerge, desta unidade de significado, que os registros da enfermeira possibilitam planejar um cuidado que favoreça todos os aspectos do crescimento e desenvolvimento da criança.

As anotações do enfermeiro, no que se refere à puericultura, são para orientar o trabalho, direcionar o trabalho desenvolvido com a criança. Acompanhando a criança, a gente tem noção para se orientar no trabalho que a gente vai desenvolver com aquela criança, observando o seu desenvolvimento até a idade em que ela for acompanbada na puericultura (E7).

\section{Registro/anotação de enfermagem na continuidade do cuidado}

As enfermeiras mostraram, em seus relatos, que os registros de enfermagem podem promover a continuidade da assistência à criança entre a equipe multiprofissional.

A gente precisa anotar de forma bem objetiva também, para que os dados e as anotações não se percam e possam servir no acompanhamento, e que qualquer profissional que pegar os registros possa dar continuidade e entender como é que está sendo feito o acompanbamento da criança (E7).

Outras retrataram que o registro de enfermagem permite a continuidade da assistência à criança e, se não se registram os dados da consulta de enfermagem, não se tem informações coletadas em consultas anteriores, como bem retrata a fala desta entrevistada:

[...] Tenho notado que cada vez mais os registros não me trazem informação. Faltam informações do que fiz anteriormente (E5).

Também merece destaque a fala da entrevistada que faz uma crítica aos registros de alguns profissionais.

O que eu percebo é isso: que alguns profissionais, além de não registrar, só colocam assim: a dieta da criança, as medidas e não anotam, por exemplo, se pedem exame ou não, se a criança esteve internada. Essas coisas que eu acho importante (E4).

Como se apreende desses dizeres, o registro de algumas enfermeiras apresenta-se fragmentado, não permitindo a continuidade e a visualização do cuidado prestado à criança.

Parece claro o entendimento de que o registro de enfermagem bem feito é fundamental para a prestação de uma assistência de enfermagem de qualidade, contudo, na prática, essa valorização não acontece.

Agora acho que o registro deve ser feito, apesar de não o fazer, pois se a criança está sob meus cuidados, tudo vai bem. Mas se ela é transferida para outro Centro de Saúde onde háprofissionais que trabalham de forma diferente. Por exemplo, se transfiro ela para você, e sua forma de trabalho é diferente... Então acho que o registro tinha que ser mais detalhado (E6). 


\section{DISCUSSÃO}

O registro é um dos canais de comunicação, escrito, utilizado pela equipe de enfermagem no desenvolvimento de suas ações. Quando bem elaborado, permite a individualização do cuidado, refletindo a qualidade da assistência prestada. Constitui, também, documento legal para a equipe de saúde, para o cliente e para a instituição, pois faz parte da documentação da assistência ao cliente, representando o testemunho escrito na defesa legal dos profissionais envolvidos nessa assistência.

Os registros nos dão respaldo e são nossa defesa legal. Comprovamos o nosso trabalho através deles, visto que o nosso trabalho é um serviço que se consome no momento de sua realização ${ }^{(13)}$.

Um aspecto que nos chamou a atenção é o fato de as enfermeiras não se preocuparem com os princípios éticos e legais da profissão. Não assinam o que escrevem, o que fazem, então, é de todos, não é de ninguém. Perde a identidade. Para que um documento funcione como instrumento legal é preciso que seja assinado e datado, do contrário, poderá não ser aceito como prova ou ser indicativo de má qualidade do cuidado ${ }^{(14)}$.

Em estudo realizado a respeito das implicações éticas e legais das anotações de enfermagem sobre doações de órgãos, foi verificada, em $91,7 \%$ dos prontuários, a falta de assinatura ${ }^{(15)}$. Esse descuido desvenda a inautenticidade do ser, todo mundo é o outro e ninguém é si próprio ${ }^{(11)}$. Ou seja, os prontuários trazem informações que não pertencem a ninguém. Assim, elas são destituídas de sentido, porque não há responsabilidade e zelo no seu anotar.

Se é fato que os registros constituem documento legal e que devem ser seguidos da respectiva assinatura do executante, podemos considerar, então, que as enfermeiras não estão cumprindo o dispositivo legal mencionado.

A auditoria, em enfermagem, é uma forma de avaliação sistemática da qualidade da assistência prestada ao cliente, verificada através dos registros de enfermagem no prontuário e/ou das próprias condições deste. A auditoria beneficia o cliente, porque possibilita-lhe receber uma assistência de melhor qualidade e beneficia também a equipe de enfermagem porque fornece subsídios para a reflexão profissional e, conseqüentemente, proporciona oportunidade para o desenvolvimento profissional. Beneficia, ainda, a instituição, auxiliando no controle de custos e a profissão de enfermagem, fornecendo o desenvolvimento de indicadores de assistência e o estabelecimento de critérios de avaliação e geração de novos conhecimentos ${ }^{(16)}$.

O conhecimento da instituição, do serviço de enfermagem e da clientela é fundamental para o levantamento das necessidades da assistência de enfermagem a ser prestada, escolhendo o método de sistematização da assistência mais adequado para a realidade encontrada ${ }^{(17)}$. É fundamental para essa caracterização que haja informações.
Os resultados deste estudo revelaram a importância dos registros de enfermagem na construção do perfil epidemiológico, possibilitando o diagnóstico da comunidade, visando ao planejamento das ações de saúde e a implementação de um método de assistência de enfermagem. Esses diagnósticos, além de permitirem um planejamento realista, contribuem também para posterior avaliação do impacto das ações implementadas.

Esse cuidar possibilita uma transformação da prática assistencial de enfermagem, na medida em que o enfermeiro utiliza o "saber" epidemiológico no seu "fazer", no seu processo de trabalho, superando, assim, o modelo médico individual e fragmentário. Valoriza, ainda, ações de vigilância epidemiológica e outras de intervenção não restrita à estrutura física da unidade de saúde, e reconhece a criança como ser-no-mundo e ser de cuidado.

Diante disso, é necessário que a enfermeira registre as ações de sua consulta, a fim de proporcionar dados que irão complementar as informações necessárias para a realização do diagnóstico comunitário de saúde infantil.

Durante uma consulta de enfermagem para avaliação do $\mathrm{CD}$, a enfermeira utiliza gráfico, observa o desenvolvimento, o ganho ponderal e o de estatura, faz levantamentos do estado de saúde da criança, além das necessidades e preocupações dos pais. Compartilha com a criança e a família as informações e os conhecimentos de enfermagem, a situação da criança relacionada à alimentação, imunização, sono e repouso, lazer, relacionamento familiar. Em cima desses fatores levantados e registrados, o enfermeiro deve planejar um cuidar que favoreça todos os aspectos do crescimento e desenvolvimento da criança.

Nesse sentido, devemos zelar pelos nossos registros, pois registrar também é uma forma de cuidar e de permitir a continuidade do cuidado.

O acompanhamento do CD é realizado por uma equipe multiprofissional: médico, psicólogo, odontólogo, assistente social, enfermeiro, auxiliares e técnicos de enfermagem, fisioterapeuta e outros, numa abordagem promocional da saúde.

A criança necessita receber o cuidado de forma sistematizada, interdisciplinar e holística, e os profissionais envolvidos nesse acompanhamento, precisam estabelecer e manter uma comunicação entre si: uma comunicação escrita de todas as ações que se relacionarem à criança, mas, também, uma comunicação oral cujo discurso seja claro, objetivo e subjetivo e entre sujeitos coexistentes com formações diferentes, mas unificados pelo mesmo cuidar humano.

Assim sendo, as anotações de enfermagem são indispensáveis no prontuário da criança, considerando que a enfermeira é a profissional que realiza maior número de consultas à criança, visto que, além das consultas realizadas para o acompanhamento do CD infantil, também realiza consultas para o atendimento de queixas como resfriado, dermatites, diarréia, dor e outras. Nesse 
sentido, precisa manter uma comunicação eficaz com todos os membros da equipe. Uma comunicação que faz brotar a interação, a interrelação e a intercomunicação.

A falta de registro traz conseqüências, problemas de produtividade, "retrabalho", prejuízo no atendimento às necessidades da criança e prejuízo para a continuidade da assistência ${ }^{(18)}$.

Em estudo sobre os registros de enfermagem, percebeu-se que a documentação do cuidado ao ser humano ainda é feita de forma fragmentada, e isto leva a questionar se o cuidado é realizado desta forma ou se apenas o registro do cuidado é assim ${ }^{(19)}$.

Essa deficiência na articulação/circulação da informação entre os diversos contextos da prática dificulta a tomada de decisão em enfermagem e a continuidade dos cuidados prestados ${ }^{(20)}$.

Precisamos valorizar nossos registros para que eles realmente se tornem um espelho do cuidado prestado, mas um espelho que reflita a imagem de um cuidado integral, individualizado e autêntico.

\section{CONCLUSÃO}

Diante do exposto e do caminhar deste estudo, o significado que as enfermeiras atribuem às anotações/registro

\section{REFERÊNCIAS}

1. Matos SS. Comunicação escrita das ações de enfermagem: uma contribuição ao ensino da graduação [dissertação]. Belo Horizonte: Escola de Enfermagem da Universidade Federal de Minas Gerais; 1997.

2. Matsuda LM, Silva DMPP,Évora YDM, CoimbraJAH. Anotações/ registros de enfermagem: instrumento de comunicação para a qualidade do cuidado? Rev Eletrônica Enferm. [Internet]. 2006;8(3):415-21. [citado 2008 Maio 18] Disponível em: http:/ / www.fen.ufg.br/revista/revista8_3/v8n3a12.htm

3. Santos SR, Paula AFA, Lima JP. O enfermeiro e sua percepção sobre o sistema manual de registro no prontuário. Rev Latinoam Enferm. 2003;11(1):80-7.

4. Fernandes MGM, Assis JF, Barreto EF. Registro das ações de cuidado no contexto da enfermagem clínica: análise do conteúdo. Nursing (São Paulo). 2001;4(37):31-4.

5. Canello BL, Muntsch S. Projeto de implantação das anotações de enfermagem em unidade de terapia intensiva pediátrica. Rev Bras Enferm. 1998;51(2):321-36.

6. Oliveira PS, Nóbrega MML,Silva ATMC, Ferreira Filha MO. Comunicação terapêutica em enfermagem revelada nos depoimentos de pacientes internados em centro de terapiaintensiva. RevEletronica Enferm [Internet]. 2005;7(1):54-63. [citado 2008Maio 20]Disponível em: http://www.fen.ufg.br/revista/revista7_1/original_05.htm

7. Grespan Suarez G, Albini L, Segui ML̄H, Paganini MC. Anotações de enfermagem: padronização no Hospital de Clínicas da UFRP. Cogitare Enferm. 2000;5(N Esp):12-5.

8. Oliveira VC, Cadete MMM. A consulta de enfermagem no acompanhamento do crescimento e desenvolvimento infantil. REME Rev Min Enferm. 2007;11(1):77-80.

9. Silva MJP, Dias DC. O registro da prática da enfermagem: da realidade do cuidado rotineiro à utopia do cuidado individualizado. Nursing (São Paulo). 1999;2(11):21-6.

10. Bicudo MAV, Espósito VHC, organizadoras. Pesquisa de suas ações possibilitou-nos compreender que estes não só fazem parte do cuidado de enfermagem, mas integram os próprios cuidados. Quando registramos, nós nos preocupamos com o outro, seja cliente, equipe de saúde, instituições de proteção à saúde da criança, entre outros.

A pesquisa evidenciou um grande conhecimento dos entrevistados acerca da importância de registrar o cuidado de enfermagem prestado à criança. De forma adequada, descrevem as finalidades do registro no processo do cuidar humano. Porém, o que se observa é que esse conhecimento não está sendo suficiente para garantir ou para dar segurança à enfermeira, no momento que ela precisa utilizar desse conhecimento. Porque, apesar de as enfermeiras entrevistadas reconhecerem a importância de se registrar todos os dados, todas as ações referentes ao acompanhamento do crescimento e desenvolvimento infantil, na prática, este registro continua incompleto, inconsistente, impróprio e inautêntico.

Registra-se, assim, a premência de incorporar à graduação o ensino continuo da comunicação escrita, em todas as dimensões e espaços do processo ensinoaprendizagem, e dar continuidade a estes estudos nos diversos fóruns de encontro dos enfermeiros. Acredito que estas estratégias poderão erigir e manter o cuidado solícito e autêntico no acompanhamento do crescimento e desenvolvimento da criança.

qualitativa em educação: um enfoque epidemiológico. Piracicaba: Editora UNIMEP; 1994. p. 15-79

11- Heidegger M. Ser e tempo. 3a ed. Petrópolis, RJ: Vozes; 1989.

12- Martins J, Boemer MR, Ferraz CA. A fenomenologia como alternativa metodológica para pesquisa: algumas considerações. Rev Esc Enferm USP. 1990;24(1):139-47.

13- Cosentino SF, Lunardi Filho WD. Anotações/registros de enfermagem: uma prática educativa em busca de uma outra ação. Texto \& Contexto Enferm. 2000;9(2):147-57.

14- Oguisso T. Os aspectos legais da anotação de enfermagem no prontuário do paciente [tese]. Rio de Janeiro: Escola de Enfermagem da Universidade Federal do Rio de Janeiro; 1974.

15- Dalri MCB, Rossi LA, Carvalho EC. Aspectos éticos e legais das anotações de enfermagem nos procedimentos de doação de órgãos para transplantes. Rev Esc Enferm USP. 1999;33(3):224-30.

16- Pereira LL, Takahashi RT. Auditoria em enfermagem. In: Kurcgant P, coordenadora. Administração em enfermagem. São Paulo: Editora Pedagógica e Universitária; 1991. p. 215-22.

17- CastilhoV,GaidzinskiRR. Planejamentoda assistência de enfermagem. In: KurcgantP, coordenadora. Administração em enfermagem. São Paulo: Editora Pedagógica e Universitária; 1991.p. 207-14.

18- Souza V,MouraFL, Flores ML. Fatores determinantese conseqüências de falhas registradas na assistência de enfermagem: um processo educativo. REMERev Min Enferm. 2002;6(1/2):30-4.

19- Dias DC. Análise de evoluções de enfermagem segundo o referencial teórico de Horta e o sistema operacional de Weed [dissertação]. São Paulo: Escola de Enfermagem da Universidade de São Paulo; 1998.

20- Sousa PAF, Frade MHLBC, Mendonça DMMV.Um modelo de organização e partilha de informação de enfermagem entre hospital e centro de saúde: estudo delphi. Acta Paul Enferm [Internet]. 2005; 18(4):368-81. [citado 2008 Jun 16] Disponível em: http:/ / www.scielo.br/scielo.php? script $=$ sci_arttext\&pid $=$ S0103$21002005000400005 \& \operatorname{lng}=$ pt\&nrm $=$ iso 